\title{
OBSERVATIONS ON OPTOMETRY IN THE VETERAN'S ADMINISTRATION FROM AN OPTOMETRIC EDUCATOR'S PERSPECTIVE
}

\author{
John F. Amos, O.D., M.S., D.O.S. \\ Dean and Professor Emeritus, \\ UAB School of Optometry \\ Birmingham, Alabama \\ eyedoc@uab.edu
}

doi 10.14434/hindsight.v51i3.31038

\begin{abstract}
This invited address was presented at the $42^{\text {nd }}$ Annual Meeting of the National Association of Veteran's Administration Optometrists (NAVAO), Thursday, October 24, 2019, Hyatt Regency Hotel, Orlando, FL. This paper discusses medicine, dentistry, and optometry's entry into the Veteran's Administrations System as well as optometry's many challenges to become an Optometry Service. It also reviews the many challenges the profession has faced as it has endeavored to increase the number of VA optometry staff positions and the educational experience of optometry students, residents and fellows in providing eye care for America's veterans.
\end{abstract}

\section{KEYWORDS}

Optometry history; optometry in the Veteran's Administration; optometric academic affiliation; optometric externships; optometry residencies; growth of optometry in the VA.

\section{INTRODUCTION}

I am honored to be invited to speak to the members and guests of this distinguished organization. I must confess that the comments I make tonight are from the perspective of someone who spent almost all of his career in optometric education. Nevertheless, I was privileged to either observe, or be part of some of the important events that occurred in the Veterans Administration (VA) related to optometry, even if my involvement was somewhat tangential in nature. I am going to briefly discuss medicine and dentistry's VA history, how optometrists were permitted to examine VA patients, the first affiliation with a school of optometry's professional program (O.D.), the Director of Optometry Service's many challenges, optometry residency programs, externships, and the growth of optometry in the VA. Like almost all of optometry's efforts to grow, this relationship with the VA did not occur quickly and certainly was not easy.

\section{MEDICINE AND DENTISTRY'S FOUNDATION IN THE VA}

To better understand optometry's many challenges in achieving its present standing in the VA it may be of value to understand medicine and dentistry's historical foundation related to the VA. It is an interesting history but perhaps one that is not surprising.

The irony of all that has occurred with regard to VA optometry, was the fact that medical schools had refused to affiliate with the VA hospitals prior to 1946, fearing it as the beginning of "socialized medicine". From 1930 until 1945 the VA medical system operated a modest collection of outdated facilities often inherited from the military or state sanitariums and "soldiers" homes. VA physicians and dentists were federal civil servants recruited from US civil service rolls, were older or close to retirement, and poorly paid. There was no affiliation with medical or dental schools and no training occurred in their facilities.'

\section{Reforms in the VA following WW II}

With World War II over, millions of men and women in the armed forces were returning to civilian life, many with continuing medical needs. President Truman asked General Omar Bradley to leave the Army and administer the reforms he knew were necessary. Bradley recruited retired Major General Paul Hawley, MD, Northwestern University Professor, Paul Magnuson, MD, and like-minded colleagues, and members of Congress, especially those interested in the long-term welfare of veterans.

Among the first changes were amendments to United States Code, Title 38 that removed physicians and dentists from the Civil Service Commission and created a new, independent, VA "Department of Medicine and Surgery". This included a personnel department offering competitive salaries to recruit higher quality physicians and dental staff. It took many years, substantial changes to regulations, new statutory authorities and many millions and, later billions of dollars, to build facilities and modernize the VA after WW II. However, once medical schools were affiliated, they fought very vigorously against including optometry, especially from 1972 through 1978.

\section{EARLY YEARS OF OPTOMETRY IN THE VA}

\section{First Optometrists}

Optometrists were first placed on the staff of Veteran's 
Administration hospitals in 1947, following the end of World War II. I believe I am correct in saying that all of these positions were part-time in nature. If I am not mistaken, one of these optometrists was Dr. Richard Hopping, who, at this time practiced optometry in Dayton, Ohio. ${ }^{3}$ Unfortunately, the names, dates of employment, or locations of the other optometrists employed by the VA during this period could not be located.

\section{Specific Authority for Optometrists}

Some 10 years later, in 1957, Public Law 85-96 was enacted which provided specific authority, through United States Code, Title 38, for the employment of additional optometrists. Subsequent legislation enacted in 1958, Public Law 85-464, required VA optometrists to hold a valid state license and have graduated from an accredited and approved United States school or college of optometry. Another law, Public Law 85-857, accepted District of Columbia licensure for employment. In 1958, Public Law 85-462 and later in 1960, Public Law 86-598, were enacted which authorized optometrists to render care to eligible veterans for "medical services". The purpose of the enactment of these acts was to prevent optometrists from being excluded from providing such services since optometrists were not specifically included in the original 1946 law. $^{1}$ As late as 1972 there were only 9 optometrists among 182 VA hospitals and hundreds of outpatient clinics. ${ }^{1}$ This number did begin to slowly change but it would be another decade before significant growth occurred.

\section{FIRST OPTOMETRIC TRAINING PROGRAM AFFILIATED WITH THE VA}

\section{Dr. Peters Appointed to the Dean's Committee}

My first contact with the VA was shortly after joining the faculty of the University of Alabama at Birmingham, School of Optometry (UABSO) in August 1972. This was an indirect contact, but one of which UABSO faculty were generally aware. Dr. Henry B. Peters, who was appointed the first Dean of UABSO in August 1969, was offered, on the recommendation of Dr. Clifton Meador, Dean of the University of Alabama School of Medicine at UAB, an appointment as a member of the Dean's Committee of the Birmingham Veteran's Administration Hospital (BVAH). Dean Peters was pleased to accept this appointment as a member of the Dean's committee. This appointment was made by Dr. M. J. Musser, Chief Medical Director of the Veteran's Administration Central Office (VACO). ${ }^{4}$

As a result of this appointment, Dr. Peters realized, perhaps as early as 1969, and certainly by early 1970, there existed a possible relationship with the VA and more specifically the Birmingham Veteran's Administration Hospital (BVAH). The University of Alabama Medical Center administration and the University of Alabama Medical School at UAB were most helpful in making sure this would be among the best optometry schools in the U.S. and did much to assist Dean Peters. ${ }^{4}$

\section{PLANNING FOR AFFILIATION AND OPTOMETRIC TRAINING PROGRAM}

Dr. Peters entered into discussions with the VA for the development of a pilot optometry program during the academic year 1970-71. The purpose of this program was to provide clinical training for fourth-year optometry interns from the UABSO and optometric technicians from the Regional Technical Institute (RTI). These programs were to be located in the BVAH. ${ }^{4}$

With the support and encouragement of Mr. Clyde Cox, Director of the BVAH, Dr. S. Richardson Hill, Vice President for Health Affairs of the University, and Martha Phillips, Director of Allied Health Manpower, VA Department of Medicine and Surgery, an affiliation was negotiated with the Birmingham VAH for a teaching clinic for optometry and faculty support. ${ }^{5}$

The Medical School of the University of Alabama at Birmingham had a contract with the Veterans Administration Hospital for the exchange of faculty and services that was broad enough to include the School of Optometry. With the support of Mr. Clyde Cox, the VA Hospital Administrator, Dr. S. Richardson Hill, Vice President for Health Affairs of the University, and Martha Phillips, Director of Allied Health Manpower, VA-DM 7S, Washington, D.C., an affiliation was negotiated with the VA Hospital for a teaching Clinic for Optometry and faculty support.

A proposal was developed by Dr. Peters, Mr. Cox, and representatives of the Research and Education Service at the VACO during the summer and fall of 1971. It was submitted on October 18, 1971 and requested funding for renovation of existing space in the BVAH, purchase of equipment, and support for faculty and staff as well as stipends for the optometric technician students. ${ }^{4}$ The contract for the necessary remodeling was signed November, 1971. S Supplemental information was submitted on December 22, 1971 that provided more detailed financial information regarding the program. ${ }^{4}$

\section{Optometry Training Program Approved}

As early as February 2, 1972 the Director of the BVAH was notified of the approval for affiliation and the funding for the pilot program. In March 1972, Dr. Peters received word of the approval for the proposal. ${ }^{4}$ In November 1972, the Director of the BVAH issued a memorandum pertaining to the Policies and Procedures for Patient Services in the Optometry Program. The facility was ready for occupancy on December 1, 1972.5 A position description was signed by Dr. Jeffrey Keller as Chief, Optometry Service on December 12, 1972. ${ }^{4}$ The renovation and installation of equipment was completed by end of December, 1972 and patient care began in early January, 1973. ${ }^{6}$

The establishment of this program was a watershed moment for the profession of optometry. Dr. Robert Newcomb was appointed Chief of the Optometry Service in December 1975.' This affiliation with the BVAH continues today but has been significantly expanded in terms of size and staff and shares a large clinic space with ophthalmology at the BVAH. It also provides optometry services at other outpatient facilities in the area.

The history of how this important program came into being has been thoroughly described. ${ }^{4}$ This article details the many issues and challenges Dr. Peters confronted as he established this unique program. In retrospect, Dean Peters was the right administrator at the right time to bring this program to fruition. The profession owes Dr. Peters a debt of gratitude for this benchmark achievement. 


\section{VETERAN'S HEALTH CARE EXPANSION ACT OF 1973}

On August 2, 1973 President Nixon signed Public Law 93-82 the Veteran's Health Care Expansion Act. This act established such programs as the Civilian Health and Medical Program of the Uniformed Services (CHAMPUS) and greatly expanded health care services for veteran's, their dependents, and veteran's survivors. It also established the position of Director of Optometry.

\section{Director of Optometry Services}

I clearly remember meeting the new Director of Optometry, Dr. Kenneth Myers, at the American Academy of Optometry (AAO) meeting held at Miami Beach, FL in December 1974. This position had been established in 1973 but Dr. Myers was not appointed to this position until September 1974. ' Many of us looked forward to meeting Dr. Myers and finding out how many optometry positions were being created. Little did we realize he had no budget, office, staff, or positions to fill. This left Dr. Myers in the unenviable position of having no funding, and even if funding was available, the pay grade was not competitive with salaries in the military or private sector.

To further complicate matters, the original language of the bill described the position as Director of Optometry Services, however, in the mark-up process the title mysteriously became the Director of Optometry with the word "Services" being omitted. The omission of this one word caused several year's delay in optometry even beginning to realize its potential within the VA. ${ }^{1}$

Dr. Myers attended the 1974 AAO meeting with his immediate supervisor Dr. Thomas J. Radley. Dr. Radley was an orthopedist by training who left practice in Cincinnati, Ohio as a result of health reasons to join the VA in October 1973. Coincidently, he was a friend of Dr. John Zettel, an optometrist from Cincinnati who was a past president of the AAO in 1971-72.

As a result of this relationship with Dr. Zettel, Dr. Radley had a favorable impression of optometry. Dr. Radley took Dr. Myers under his wing during those early years. Dr. Radley was in charge of all prosthetic devices for the VA and he provided Dr. Myers a desk and relegated him to the prosthetic department to oversee the VA eyeglass contract. Dr. Myers did his best to visit VA optometry facilities, mostly in the immediate area, and attend national meetings. Clearly, this had to be a frustrating time for Dr. Myers. $^{2}$

\section{FIRST OPTOMETRY RESIDENCY PROGRAM IN THE VA}

My younger brother, Dr. David Amos was offered a position at the University of Kansas, Department of Ophthalmology, as a full-time Clinical Assistant Professor in 1972. This position was an outgrowth of an OD/MD committee that had been established in Kansas to foster better relationships between the two professions. $\mathrm{He}$ also served as a consultant to the Kansas City VAH.

\section{Initial Contact with Dr. Myers}

In 1975, Dr. Amos called Dr. Myers to inform him he thought that Dr. Albert Lemoine, Chairman of the University of Kansas, Department of Ophthalmology, might be willing to work with VA optometry. Obviously, Drs. Amos and Lemoine, had been discussing, on some level, possible programs that might involve optometry at the Kansas City VAH and increase the availability of eye services to veterans. Dr. Lemoine was well aware of the need for more accessible eye care at the Kansas City VAH. They agreed that Dr. Amos would follow-up on this conversation with Dr. Myers. Although they had never met, Dr. Amos called Dr. Myers about the possibility of a program at the Kansas City VAH.

Within a short period of time Dr. Myers flew to Kansas City to make courtesy calls on the VA Hospital Director and the Chief of Staff. Dr. Amos then took Dr. Myers on a tour of the Kansas City VA Eye Clinic. The VA clinic was small, with one part-time ophthalmology resident as its staff, and the equipment appeared to be in poor repair. At this point in time, it was not uncommon for VA ophthalmology departments to be small, understaffed, with long waiting lists. In many instances, these programs were staffed by third-year ophthalmology residents who preferred to be in the operating room than in the eye clinic looking for surgical cases. Unfortunately, in some situations the VA facility offered no eye care of any type. ${ }^{8}$

\section{Agreement to Establish an Optometric Residency Program}

In the VA of 1975, there were several hundred ophthalmologists and several hundred ophthalmology residents to only eight or nine optometrists. ${ }^{1,3}$ The division of labor in the military and many health maintenance organizations was two or three optometrists to one ophthalmologist. For all of these reasons, Dr. Myers thought that jointly staffed ophthalmologist-optometrist eye clinics would benefit both VA patients and optometry clinical training programs. For 30 years, VA eye care had essentially been rendered by the teaching ophthalmology clinics. If the VA Hospital wasn't a teaching hospital, then often it had no eye care. ${ }^{8}$

Much to Dr. Myers surprise Dr. Lemoine wanted to improve eye care at the Kansas City VAH. Dr. Lemoine also shared Dr. Myers vision and was interested in a joint program and saw no reason optometry should not fit into a medical model as colleagues. After Dr. Myers discussed several program options with Drs. Amos and Lemoine, and a KCVA Hospital Administrator, they agreed that an optometry residency program was the best type of program to pursue. They all agreed with the concept and set about bringing it to reality. ${ }^{7,8}$

To this end, Dr. Amos was to contact Dr. Alfred Rosenbloom, President of the Illinois College of Optometry (ICO), located in Chicago, IL to determine if they would be interested in affiliating with the Kansas City VAH. Dr. Lemoine would ask the VA for additional space and equipment for the Kansas City VAH. Dr. Myers would request funding from the VACO to pay the optometry resident. As it turned out, the optometry resident was paid the same amount as a first year medical or dental resident. ${ }^{8}$

In spring before the 1975 graduation at ICO, Drs. Amos and Lemoine flew to Chicago, IL. The purpose of the trip was to meet with Dr. Alfred Rosenbloom, President of ICO, and secure an academic affiliation. Dr. Rosenbloom embraced the program and offered strong support and encouragement. Their purpose was also for Drs. Lemoine and Amos to have an opportunity to speak to all of the optometry students at (ICO) about such a program. Dr. Lemoine's support no doubt proved crucial because funding was in place by summer and the program began in July 1975.' Dr. Myers noted in his 2010 paper on "Public Health and the 
Department of Veteran's Affairs", that the VACO did not realize that there were no existing accredited optometry residency programs prior to this time. ' It is the quickest I have ever heard of the VA authorizing a new program!

\section{First Resident at Kansas City VA}

A 1975 ICO graduate, Dr. Thomas Stelmack, became the first VA optometry resident. Dr. Stelmack completed the program in 1976 and had high praise for the experience. ${ }^{3}$ He was followed by many residents of this program who have had distinguished careers in the profession. ${ }^{9}$ This program remains an excellent $V A$ residency site with a strong low vision component. Dr. Robert Carty served as the first Director of the Kansas City VA Optometry Service and deserves much of the credit for its long-term success. ${ }^{3,7}$ As part of the program's $25^{\text {th }}$ Anniversary, Maino surveyed residents who had completed the program and presented data on a number of outcomes related to reasons for selecting this program. Among the reasons given were the number and diversity of patient encounters, opportunity to diagnose and treat eye disease, low vision rehabilitation experience, interaction with ophthalmology, interaction with others including the staff, personal responsibility and didactic opportunities such as teaching, research, and publication, as well as other aspects of the residency program. ${ }^{9}$

\section{VETERAN'S OMNIBUS HEALTH CARE ACT OF 1976}

\section{Optometrists Placed on Title 38}

The Veterans Omnibus Health Care Act did for optometry what the original 1946 law did for physicians, dentists and nurses. Against the recommendation of the VA, Congress added language to the bill that became Public Law 94-581 and addressed several important goals. It included a mandate for a VA Optometry Service, removed optometrists from the Civil Service pay and personnel system and placed them in the same pay and personnel system, Title 38 of the U.S. Code, as physicians and dentists.

It also directed the VA to appoint optometrists and create teaching affiliations with schools and colleges of optometry. It also created the prestigious Special Medical Advisory Group (SMAG). However, progress remained slow. Even though Congress may legislate, agencies implement and can stall, defer, or kill a congressional mandate. It was becoming obvious that optometry was facing stiff opposition from medicine. ${ }^{1}$

\section{Resistance to Optometry}

After the Veteran's Omnibus Health Care Act legislation passed on October 21, 1976 very little happened on the optometry front. As a result of this slow progress, in early Spring 1977, a joint American Optometric Association-Association of Schools and Colleges of Optometry (AOA-ASCO) Report was presented to the VA's Central Office, Department of Medicine and Surgery, offering detailed recommendations for Public Law 94-581. This marked the first-time optometric education added their support for integrating optometry care and teaching programs into the VA system.

\section{Southern California College of Optometry Receives Training Grant}

In September 1976, the Southern California College of Optometry had secured a seven-year manpower training grant for, among other issues, determining how optometric clinical education was being incorporated into the VA system. The training grant was in the amount of $\$ 936,050$ and was to be utilized to determine how resources were being allocated for eye care, including the use of optometrists in the VA. The grant had been made available under Public Law 92-541. ${ }^{3}$ This training grant was conducted at the downtown VA Outpatient Clinic in Los Angeles, CA. The grant was under the direction of Dr. Jerry Jolley, Director of External Clinical Programs. Dr. Lauren Fisher led the program for three months before the arrival of Dr. Gerald Selvin, in December 1976. ${ }^{11}$

This program was well underway by the time of Dr. Selvin's arrival. Monthly Reports submitted by Dr. Selvin helped establish data for the unmet eye care needs in the VA. This data proved of great value in the ultimate development of the General Accounting Office (GAO) Report. 3,11 The joint project team of the AOA-ASCO report that was submitted to the VACO had Dr. Peters as one of its chief authors.

\section{General Accounting Office (GAO) Report}

In 1978, the GAO, using information from the AOA-ASCO Report, issued its report entitled "The Role and Use of Optometry in the VA Need Improvement", making clear the documented resistance of ophthalmology and the lack of serious attempts by the VA Central Office to implement the creation of an optometry service." ${ }^{3}$ In spite of this report it required a congressional hearing before it was made clear to VA Central Office that Congress expected optometry to be fully integrated into the VA.

Senator William Proxmire, Chairman of the Senate Subcommittee on HUD-Independent Agencies, asked the GAO to investigate the extent to which medical schools influenced appointments at VA Hospitals. Senator Alan Cranston, Chairman of the Senate VA Committee, asked Senator Proxmire to include a GAO report on whether the VA was implementing the optometry portions of Public Law 94-581.' Finally, later in the year, funding was made available for the employment of 34 optometrists and the support of teaching affiliations.'

\section{Rear Guard Action by Medicine}

Predictably organized ophthalmology and the AMA viewed the nascent VA optometry action as an "incursion" into the VA. An AMA committee drafted Resolution \#155 opposing the employment and training of optometrists in VA hospitals and asking for repeal of PL 94-581. VA Chief Medical Director, Dr. Donald Custis, a former Navy Surgeon General, appeared before the AMA Congress in Chicago to argue against the resolution. Dr. Custis knew about the wide use of optometrists in military medical systems. As a result of his action, this resolution was pulled but the medical resistance remained.

Once again, it was the combined actions of the AMA Committee, the American Academy of Ophthalmology and the Physicians Education Network (PEN), that convinced the VA Central Office that for optometry to be treated equitably, it had to ensure 
the independence of optometry as a service. It was clear that placing optometry under ophthalmology supervision would not allow optometry to thrive. Finally, by 1978 the way was clear, in theory, to construct an optometry service but still no funding to accomplish this goal was provided by Congress. ${ }^{1}$

\section{Appointment as UABSO Director of Optometry Residencies}

The rapid approval of the residency program at the Kansas City VAH provided a stimulus for many other VA hospitals and schools and colleges of optometry to begin residency programs. In 1978, after the acceptance of a proposal originally submitted in 1974, I was appointed as Director of the UAB School of Optometry's Residency Programs. UAB was one of the first, if not the first, school-based one-year Council on Optometric Education (COE) accredited residency programs. Alabama has a number of VA facilities including hospitals in Birmingham, Tuscaloosa, Montgomery, Huntsville and Tuskegee.

The School of Optometry received permission to begin its residency programs in September, 1978. The programs approved were for two residents in Family Practice Optometry and one in Low Vision Rehabilitation. Within two years, the Low Vision Rehabilitation Residency Program had been transferred to the Birmingham VAH and another Hospital-Based Residency Program had been established at the Tuscaloosa VAH. The locations of these hospitals were in close proximity to the UAB campus and residents could participate in the Conference Series that is such an integral part of the program. Within a decade Dr. Peters had submitted a grant to the VA to establish the Southeastern Blindness Rehabilitation Center at the BVAH in 1982. ${ }^{5}$ It was one of the earliest such Blindness Rehabilitation Centers (BRC's) established in the U.S. These residency programs would provide future personnel for VA staff positions and faculty for schools and colleges of optometry.

\section{RAPID INCREASE IN THE GROWTH OF OPTOMETRIC SERVICES}

Between 1976 and 1990 the Optometry Service experienced steady, if sometimes, slow growth. The VA remained a centralized system and funding was difficult to obtain. However, by the mid1970's new approaches to administration were finally beginning to occur. This was brought about as a result of changing health care demographics such as the aging of WW II veterans, the influx of veterans from the Vietnam Conflict, the Gulf Wars, Iraq and Afghanistan deployments. It was also hastened by new treatment techniques not requiring hospitalization and the need for better surveillance of such chronic conditions as diabetes and hypertension.'

\section{Decentralization of VA System}

Decentralization was finally occurring in the VACO and funds were being allocated in a manner different than before. Greater authority had been transferred to each VA hospital. By the late 1980's and early 1990's, with more control being given to each VA facility, it was evident that positions were being funded by decisions and needs made locally. Much of this change was sparked by Undersecretary of Health, Dr. Kenneth Kizer.

With the need to provide community outreach eye care and mandated treatment regimens that required annual eye examinations, along with the growth of ambulatory treatment centers and the greater emphasis on the value of quality eye care, the number of staff optometrists rapidly increased during the 1990's.' The goals of optometry as a primary eye care profession and the needs of the VA made for a symbiotic relationship that benefitted both entities.

\section{THE VALUE OF EXTERNSHIPS}

There is one other area of optometric education I would be remiss if I did not mention. The schools and colleges of optometry developed an early relationship with the VA in the establishment of externship sites. Beginning in the late 1980's there was a growing need to keep pace with the changes in the expansion of scope of care the optometry profession was experiencing. Some schools and colleges had implemented externships as early as the mid-1970's. I was involved in the beginning of UAB's externship program along with Dr. Lester Caplan in 1991.12

Although every school or college has many externship sites, clearly some of the best patient care experiences have been those externships in VA facilities. In fact, many externship programs have a VA site as a mandatory rotation for fourth year students. The profession has embraced the need for and value of externships in providing the quality of optometric education necessary for contemporary graduates. These externships also offer students exposure to the value inherent in a VA optometry residency program. I believe many fourth-year optometry students have chosen a VA optometry residency as a result of their externship experience.

\section{CONCLUSION}

In conclusion, I can't help but wonder how Dr. Peters would feel knowing that one staff optometry position begun in 1972 at the Birmingham VAH has now grown to 966 positions. ${ }^{13}$ I suspect he would be very proud. There are now many more staff optometry positions than staff ophthalmology positions. Clearly, this speaks to the ability of optometry to meet the needs of veterans in providing high quality eye care in a cost-effective manner. Obviously, many local VA facilities have discovered this as well since many of these positions are funded locally.

I know how much I appreciate that VA optometry is now the largest optometry program in the U.S. It also has the largest number of optometry residents. I am sure Dr. David Amos and other early pioneers in optometric residency education never imagined the VA would have 221 optometry residents and two research fellows and 1,400 optometry externs who are receiving excellent clinical education and training all while being exposed to the VA as a possible career choice. ${ }^{13}$

In addition, those who fostered externships in optometric education must be pleased to know that optometry students have the experience of providing eye care to America's veterans as part of the fourth-year clinical rotations.

Finally, in spite of great obstacles and many challenges, VA optometry has persevered and grown significantly. We all owe a debt of gratitude to the VA and VA optometry for the millions of dollars of support and in-kind support provided to the profession, optometric education, and our veterans. 
My congratulations to NAVAO since 10 VA optometrists had the foresight to found this organization. ${ }^{3}$ This milestone event occurred during the annual meeting of the AAO in Birmingham, AL. It is obvious the NAVAO has accomplished much since your beginning in 1977, some 42 years ago. I encourage you to continue to explore boundaries and bring forth new ideas and concepts for VA optometry and our veterans. I know that with strong leadership, the support of this organization and that of the $\mathrm{AOA}$ and $\mathrm{ASCO}$, more is possible.

I also want to express my appreciation to Drs. Myers (19741989), Mullen (1990-1996), Monaco (1997-1999) and Townsend (2000-Present) for their leadership over these past 45 years.

Thank you for inviting me. It has been a privilege to explore this important VA optometry history.

\section{ACKNOWLEGEMENT}

I want to thank Drs. David Amos, Kenneth Myers, Lester Caplan, Gerald Selvin, Robert Newcomb, and John Townsend for their willingness to share information about the history of VA Optometry and related topics.

\section{REFERENCES}

1. Myers KJ. Public Health and the Department of Veterans Affairs. In: Public Health in the Department of Veterans Affairs. Old Post Publishing, Cadyville, NY, 2010; 1-34.

2. Personal Communication. Dr. Kenneth J. Myers, August 9, 2019.
3. Newcomb RD. History of Optometry in the VA. HINDSIGHT: Journal of Optometry History. 2010; 41(1): 6-8.

4. Amos JF. The Genesis of the Optometry Training Program in the Birmingham Veterans Affairs Hospital. HINDSIGHT: Journal of Optometry History. 2013; 44(4): 50-70.

5. Peters HB. School of Optometry, University of Alabama at Birmingham. 25th Anniversary Photographic History, 19691994, 1994; 15.

6. Keller JT. Optometric Training in a Veterans Administration Hospital. Am J Optom Physiol Opt 1974; 51(6): 425-428.

7. Personal Communication. Dr. David M. Amos, August 5, 22, 23, 2019.

8. Myers KJ. Guest Editorial. Kansas City Memories. Optom Vis Sci 2002; 79(7):395-397.

9. Maino JH. Kansas City VAMC Optometry Residency Program: A Survey of Residents since 1975. Optom Vis Sci 2002; 79(7):410415.

10. Amos JF. A Brief History of Optometric Residency Education. J Am Optom Assoc 1986; 58(5): 374-375.

11. Personal Communication, Dr. Gerald Selvin, October 23, 2019.

12. Personal Communication. Dr. Lester Caplan, August 10, 2019.

13. Personal Communication. Dr. John Townsend, September 26, 2019 